\title{
The Effect of Mode of Delivery on Postpartum Sexual Function and Sexual Quality of Life in Primiparous Women
}

\author{
Hanan Abd Elwahab EI Sayed ${ }^{1}$, Soad Abd el Salam Ramadan ${ }^{2}$, Heba Abdel-Fatah Ibrahim ${ }^{2, *}$, \\ Huda Abd Allah Moursi ${ }^{1}$ \\ ${ }^{1}$ Community Health Nursing, Benha University, Benha, Egypt \\ ${ }^{2}$ Obstetrics and Woman Health Nursing, Benha University, Benha, Egypt
}

Email address:

heba.abdelfattah@fnur.bu.edu.eg (H. Abdel-Fatah I.)

${ }^{*}$ Corresponding author

To cite this article:

Hanan Abd Elwahab El Sayed, Soad Abd el Salam Ramadan, Heba Abdel-Fatah Ibrahim. Huda Abd Allah Moursi. The Effect of Mode of Delivery on Postpartum Sexual Function and Sexual Quality of Life in Primiparous Women. American Journal of Nursing Science.

Vol. 6, No. 4, 2017, pp. 347-357. doi: 10.11648/j.ajns.20170604.19

Received: June 5, 2017; Accepted: June 19, 2017; Published: July 24, 2017

\begin{abstract}
Pregnancy and delivery are one of the most significant periods of women's life that causes hormonal and bodily alterations which could have major effects on sexual function and sexual quality of life. The aim of the study was to evaluate the effect of mode of delivery on postpartum sexual function and sexual quality of life in primiparous women. A comparative descriptive design was used. The study was conducted at the family planning outpatient clinic of Benha teaching hospital. A purposive sample of 277 primiparous women were divided in two groups vaginal delivery $(\mathrm{n}=140)$ and cesarean section $(\mathrm{n}=137)$. Three tools were used for data collection; 1) Structured interviewing questionnaire to collect data about the women' demographic characteristics, gynecologic and sexual history. 2) Female sexual function index was used to evaluate sexual function of the studied women. 3) Sexual quality of life-female questionnaire. The study results showed that $65 \%$ of vaginal delivery group and $57.7 \%$ of cesarean section group had poor sexual function level, $76.4 \%$ of vaginal delivery group and $75.9 \%$ of cesarean section group had average level of sexual quality of life after delivery, which revealed no statistically significant differences $(\mathrm{P}>0.05)$ between the two groups as regard to postpartum sexual function and sexual quality of life. Moreover, there was a positive highly statistically significant correlation $(\mathrm{P}<0.01)$ between the women' sexual function scores and their sexual quality of life scores. The study concluded that there were no statistically significant differences between vaginal delivery and cesarean section groups as regard to postpartum sexual function and sexual quality of life. The study recommended that nurses should provide sexual education for women during postpartum period to enhance sexual functioning and sexual quality of life.
\end{abstract}

Keywords: Cesarean Section, Female Sexual Function, Quality of Life, Vaginal Delivery

\section{Introduction}

Sexuality is a phenomenon not to be neglected, as similar to other instinctive desires of mankind, it has existed since birth and has evolved in accordance with human development. [1] Sexual function is an important component of women's lives and has an essential role in the marriage stability and is recognized as a multidimensional phenomenon, which can be influenced by multi bio psychosocial factors. [2, 3]

Women's sexual activity changes at various stages of life and is affected by numerous factors, one of them includes childbirth and maternity that deserves a closer analysis, as it promotes significant changes in women's, husband's and family lives. These factors also include fatigue, fear of subsequent pregnancy, concern about pain during intercourse, mode of delivery, parity and tenderness of breasts which can have different results because of different culture. [4]

Postpartum sexual function is affected by changes in anatomy, hormonal milieu, family structure, and husband relationships that accompany childbirth. Although the intimacy of beginning a family and supporting a newborn may enrich many couples' sexual experience many 
postpartum obstacles may adversely influence sexual health. [5] There is a need to adapt to the demands of the newborn and the parental role that may adversely affect the intimacy of the couple, as well as changes in body image and the desexualized figure of woman, cultivated by society. [6]

According to Leal and his colleagues, women with episiotomy or perineal tears show higher pain intensity, less sexual satisfaction, lower levels of sexual arousal, lubrication, greater changes regarding the orgasm's intensity and duration, and total sexual function, than women with intact perineum and the Cesarean Section (CS) group. [7] In addition women who were breastfeeding had lower lubrication, more dyspareunia, and longer time to resume sexual activity. [8]

The rate of cesarean delivery has raised dramatically worldwide in the last decades particularly in high- and middle income countries. The explanations for this increase are multifactorial and not well-defined. Increasing malpractice pressure, changes in maternal characteristics and professional practice styles, as well as organizational, economic, cultural and social factors have all been associated in concern. [9, 10] It seems that the majority of women choices CS due to the ability to retain a successful and satisfying sex after delivery. [11]

Postpartum female sexual dysfunction is a behaviour resulting from a combination of psychological, biological, social and cultural factors, which makes a total or partial blockage of the sexual response of subjects related to desire, arousal and orgasm. It is a serious morbidity and may lead to a variety of physical, social and adverse effects on the woman. Moreover, the consequent cycle of fear might compound the initial sexual disorder and makes it more difficult to treat. [12] It has been increasingly recognized as an important public health issue with impact on the health, well-being and quality of life of women. [13, 14] So, early diagnosis and treatment is crucial to avoid later sequalae on sexual and reproductive life. However, early diagnosis may be challenged by many factors, where many women will be embarrassed of talking about sexual matters or preoccupied by the newborn after delivery, which makes it very important for the midwifery, medical, or nursing staff to raise the issue at the postnatal care settings. [13]

Sexual quality of life (SQOL) is an important issue for assessing short- and long-term outcomes due to sexual problems. [15] Sex has a fundamental role in reproductive life, that integrates physical, emotional and psychological factors and affects quality of life. $[16,17]$ The sexual quality of lifefemale questionnaire is a short tool that assesses the relationship between female sexual dysfunction and quality of life. It has good psychometric properties with beneficial role to evaluate the female SQOL in maternity care settings. [18]

Improve the nurses' awareness about the importance of patient's healthy sexual function for good quality of life and full sexual and psychological evaluation of patients will allow for early interventions and will promote positive patient outcomes and compliance with treatment pathways. [19] Healthcare professionals should evaluate women in terms of their sexual functions during both pregnancy and postpartum period. Health education, referral services for early diagnosis and treatment might contribute to the protection and improvement of the sexual health of women during the postpartum period. [20]

Nurses play a key role in the prevention, evaluation, and treatment of postpartum sexual concerns during postpartum period. They should discuss perineal pain, dyspareunia, and initiation of postpartum sexual activity before hospital discharge, assess sexual function and address concerns, including considering the use of a brief sexual function screening questionnaire, assess perineal repair if dyspareunia is present, assess urinary and fecal incontinence symptoms, encourage vaginal lubricants, particularly in breast-feeding women with a physiologic hypo-estrogenic state, consider alternative positions, and assess for postpartum mood changes, adequate rest, and time for intimacy. Postpartum sexual counselling should be a part of antenatal and postnatal follow-up that enhancing women to disclose their sexual complains and fears in order to improve their SQOL. [5]

\subsection{Significance of the Study}

During the postpartum period, women encounter numerous physical, psychological and socio cultural factors that negatively affect both sexual function and quality of life causing postpartum sexual problems. [20] It has been reported that decrease sexual function adversely affects women's quality of life and interpersonal relationships. [21]

Postpartum sexual dysfunction can influence physical, mental, and social aspects of individuals' life with a prevalence rate of $20-73 \%$ in women. [12] Research shows that the integrity of care in women is neglected, since most of the orientations of healthcare team about postpartum sexuality are limited to recommend the resumption period of sexual activity, without addressing the aspects of the quality and the strategies to deal with the changes resulting from pregnancy-puerperal cycle. [22]

It is unclear whether CS is protective of postpartum sexual complaints. Because it avoids genital tract trauma, and assumed to protect postpartum sexual function. [23] Several studies confirmed the relationship between sexual function and mode of delivery, episiotomy, and laceration. [8, 24] While other studies found no association between sexual function and delivery mode. [25, 26] These inconsistent findings require numerous studies to fill the research gap in this respect. Moreover, Eniel and Petri [27] indicated the need for more adequately powered studies based on validated tools to answer the question of effects of mode of delivery on sexual function.

\subsection{Aim of the Study}

The aim of this study was to evaluate the effect of mode of delivery on postpartum sexual function and sexual quality of life in primiparous women through:

a. Comparing postpartum sexual function between VD and CS groups. 
b. Comparing SQOL between VD and CS groups.

\subsection{Research Questions}

a. Is there a difference between VD and CS groups regarding postpartum sexual function?

b. Is there a difference between VD and CS groups regarding SQOL after delivery?

c. Is there a relationship between the studied subjects' postpartum sexual function and their SQOL?

\section{Subjects and Methods}

\subsection{Research Design}

A comparative descriptive design was used to answer the research questions.

\subsection{Setting}

This study was conducted at the family planning outpatient clinic of obstetrics \& gynecology department, Benha teaching hospital, affiliated to Benha city. This particular setting was chosen because it is the main governmental hospital. This department is specialized in providing maternity care for women with different social backgrounds.

\subsection{Subjects}

\subsubsection{Subject Type and Criteria}

A purposive sample of 277 primiparous women were recruited for the study and were divided in two groups VD $(n=140)$ and CS $(n=137)$ with the following inclusion criteria; woman having a healthy single neonate, with an interval of 3-6 months after childbirth, free from obstetric problems during labor as third or fourth degree perineal tear or other chronic disorders such as (heart disease, diabetes, hypertension, asthma or epilepsy), free from psychological disorders as (postpartum depression or psychosis) or stressful events during the last six months and willing to participate in the study.

\subsubsection{Subject Size}

Sample size was calculated based on the previous year census report of Benha Teaching Hospital. The total number of postpartum primiparous women seeking family planning methods $=900$ women (Benha Teaching Hospital Census, 2015). Sample size was calculated utilizing Yamane formula.

$$
\mathrm{n}=\frac{\mathrm{N}}{1+\mathrm{N}(\mathrm{e}) 2}
$$

Where:

$$
\mathrm{n}=\text { sample size }
$$

$\mathrm{N}=$ total population number (900).

$$
\mathrm{e}=\text { margin error }(0.05)
$$

\subsection{Tools of Data Collection}

\subsubsection{First Tool}

Structured interviewing questionnaire was developed by the researchers in Arabic language after reviewing related literature. It involved three main parts:

a) Demographic data of the studied women such as; age, educational level, occupation, residence and monthly income.

b) Gynecologic and sexual history of the studied women such as; history of circumcision, onset of menstruation after delivery, time of resumption and frequency of sexual intercourse after delivery and calm environment during intercourse.

c) Husband information such as; occupational status, age, and suffering from chronic disease.

\subsubsection{Second Tool}

The Female Sexual Function Index (FSFI) was used to evaluate sexual function of the studied women. It consists of 19 questions, making up 6 domains, namely; sexual desire, arousal, lubrication, orgasm, satisfaction, and pain. Each item yields a score ranging from 0 to 5 . Scores obtained for each item are then summed up within each domain and then multiplied by a constant factor to yield individual domain scores. The total FSFI score is the sum of scores obtained for each domain, and ranges from 2 to 36, with a higher score associated with a lesser degree of sexual dysfunction. Sexual activity was classified as good if $\mathrm{FSFI}=30$ or more, intermediate if FSFI $=23-29$ and poor if FSFI was $<23$. [29]

Table 1. Distribution of the 6 domains of FSFI, the corresponding items, their score range, and the weight factor.

\begin{tabular}{llllll}
\hline Domain & Items & Score range & Factor & Min score & Max score \\
\hline Desire & 1,2 & $1-5$ & 0.6 & 1.2 & 6 \\
Arousal & $3,4,5,6$ & $0-5$ & 0.3 & 0 & 6 \\
Lubrication & $7,8,9,10$ & $0-5$ & 0.3 & 0 & 6 \\
Orgasm & $11,12,13$ & $0-5$ & 0.4 & 0 & 6 \\
Satisfaction & $14,15,16$ & $0 / 1-5$ & 0.4 & 0.8 & 6 \\
Pain & $17,18,19$ & $0-5$ & 0.4 & 2 & 6 \\
Scale range & & & & & 36 \\
\hline
\end{tabular}

\subsubsection{Third Tool}

The sexual quality of life-female (SQOL-F) questionnaire: It was developed by Symonds et al. [28] It is a valid and reliable instrument for evaluation of female
SQOL that focuses on sexual self-esteem, emotional and relationship issues. It consists of 18 items and each item is rated on a six-point response ranged from (completely agree to completely disagree). The response categories could be scored either 1 to 6 giving a total score of (18- 
108). Higher score indicates better female SQOL. The questionnaire items were randomly distributed in order to avoid leading sentences. The items categorized in to four factors as a following:

Factor 1 (psychosexual feelings) including 7 items (item 2, $3,7,8,10,16$, and 17).

Factor 2 (sexual and relationship satisfaction) including 5 items (item 1, 5, 9, 13, and 18).

Factor 3 (self-worthlessness) including 3 items (item 4, 6 and 15).

Factor 4 (sexual repression) including 3 items (item 11, 12, and 14).

\subsection{Methods}

The study was executed according to the following steps

\subsubsection{Approvals}

A written official approval to conduct this research was obtained from the director of Benha teaching hospital that was taken and delivered to the director of the outpatient clinics, in order to obtain their agreement to conduct the study after explaining its purpose.

\subsubsection{Tools Validity}

The validity of questionnaires were reviewed for content validity by a jury of five experts in the field of community health nursing and obstetrics \& woman health nursing at Ain shams university and Zagazig university to ascertain relevance and completeness of tools. Moreover, the validity of FSFI was confirmed by Rosen et al. and Mohammadi et al. [29, 30] Content, face and construct validity of the SQOL-F questionnaire was evaluated by exploratory factor analysis by Maasoumi et al. [18]

\subsubsection{Tools Reliability}

Reliability was done by using Cronbach's Alpha coefficient test which revealed that each of the two tools consisted of relatively homogenous items as indicted by the high reliability. Internal consistency of FSFI $=0.89$ and SQOL-F $=0.85$. According to Cronbach [31] values equal or greater than 0.70 considered satisfactory.

\subsubsection{Ethical Considerations}

Permission was obtained orally from each woman before conducting the interview and after giving a brief orientation to the purpose of the study. The woman were reassured that all gathered information is confidential and used only for the purpose of the study. No name was required on the forms to ensure anonymity and confidentiality. They were also informed about their right to withdraw at any time from the study without giving any reasons.

\subsubsection{Pilot Study}

A pilot study was carried out on $10 \%$ of the sample (28) primiparous women and were excluded from the main sample. With the main purpose to test the relevance and applicability of the tools, detect any problem peculiar to the tools, determine the time needed to fill the study tools, and find out any problem that may interfere with the process of data collection. The pilot study revealed that statements of the questions were relevant.

\subsubsection{Procedures}

The study was carried out from the beginning of October 2016 to the end of April 2017, covering a period of 7 months. The previous mentioned setting was visited by the researchers two days/week (Sunday and Wednesday) from 9.00 am to $12.00 \mathrm{pm}$ according to the schedule of the family planning outpatient clinic. The researchers interviewed the primiparous women during their follow up to the family planning outpatient clinic after reviewing her medical record, ensure her health status, explained the aim of the study, and asked for participation. Upon consent to participate, women were asked to fill the questionnaires, FSFI and SQOL-F questionnaires. Average time for the completion of questionnaires (20-25 minutes). A number of interviewed women / week ranged from 9-10 women.

\subsubsection{Statistical Analysis}

Data analysis was performed using Statistical Package for Social Sciences (SPSS version 20.0) Descriptive statistics were used to describe characteristics of the study subjects (e. g. frequency, percentages, mean, and standard deviation). Test of significance (independent $t$ test, and chi-square test) was applied to test the differences between the groups. Fisher's Exact Test (FET) was used to evaluate the differences between the groups if there are small expected values. Correlation coefficient was applied to evaluate the association between the FSFI score and SQOL score. A statistically significant difference was considered at $\mathrm{p}$-value $\leq 0.05$, and a highly statistically significant difference was considered at $p$-value $\leq 0.01$, while the $p$-value $>0.05$ indicates non-significant results.

\section{Results}

Table 2. Distribution of the studied women according to their demographic characteristics $(n=277)$.

\begin{tabular}{|c|c|c|c|c|c|c|}
\hline \multirow{2}{*}{ Variables } & \multicolumn{2}{|c|}{ Vaginal delivery $n=140$} & \multicolumn{2}{|c|}{ Cesarean section $n=137$} & \multirow{2}{*}{ FET $/ \chi^{2}$} & \multirow{2}{*}{ P value } \\
\hline & No & $\%$ & No & $\%$ & & \\
\hline \multicolumn{7}{|l|}{ Age } \\
\hline$<20$ & 6 & 4.3 & 7 & 5.1 & 4.222 & $>0.05$ \\
\hline $20-<30$ & 103 & 73.6 & 105 & 76.6 & & \\
\hline $30-<40$ & 31 & 22.1 & 22 & 16.1 & & \\
\hline$\geq 41$ & 0 & 0.0 & 3 & 2.2 & & \\
\hline
\end{tabular}




\begin{tabular}{|c|c|c|c|c|c|c|}
\hline \multirow{2}{*}{ Variables } & \multicolumn{2}{|c|}{ Vaginal delivery $n=140$} & \multicolumn{2}{|c|}{ Cesarean section $n=137$} & \multirow{2}{*}{ FET $/ \chi^{2}$} & \multirow[b]{2}{*}{$P$ value } \\
\hline & No & $\%$ & No & $\%$ & & \\
\hline Mean \pm SD & \multicolumn{2}{|c|}{$27.05 \pm 3.758$} & \multicolumn{2}{|c|}{$26.55 \pm 5.495$} & $\mathrm{t}=0.662$ & $>0.05$ \\
\hline Educational level & & & & & & \\
\hline Illiterate & 2 & 1.4 & 0 & 0.0 & 3.721 & $>0.05$ \\
\hline Read and write & 16 & 11.4 & 10 & 7.3 & & \\
\hline Primary education & 62 & 44.3 & 58 & 42.3 & & \\
\hline Secondary education & 60 & 42.9 & 69 & 50.4 & & \\
\hline \multicolumn{7}{|l|}{ Occupation } \\
\hline Working & 98 & 70.0 & 102 & 74.5 & 0.681 & $>0.05$ \\
\hline Housewife & 42 & 30.0 & 35 & 25.5 & & \\
\hline \multicolumn{7}{|l|}{ Residence } \\
\hline Urban & 73 & 52.1 & 74 & 54.0 & 0.097 & $>0.05$ \\
\hline Rural & 67 & 47.9 & 63 & 46.0 & & \\
\hline \multicolumn{7}{|l|}{ Monthly income } \\
\hline Not enough & 38 & 27.1 & 34 & 24.8 & & \\
\hline Sufficient & 72 & 51.4 & 86 & 62.8 & 5.005 & $>0.05$ \\
\hline Sufficient and save & 30 & 21.5 & 17 & 12.4 & & \\
\hline
\end{tabular}

$\chi^{2}$ : Chi-Square test, FET: Fisher's exact test, $t$ : Independent $t$ test.

Table 2 reveals that there were no significant differences ( $p$ $>0.05$ ) between the two groups in relation to their age, educational level, occupation, residence and monthly income. It was clear that $73.6 \%$ and $76.6 \%$ of VD and CS groups were aged 20- $<30$ years with a mean age $27.05 \pm 3.758$ and $26.55 \pm 5.495$ years respectively. Regarding educational level,
$42.9 \%$ of VD group and $50.4 \%$ of CS group had attained secondary level of education. Furthermore, $70.0 \%$ and $74.5 \%$ of both VD and CS groups respectively were working. Also, $52.1 \%$ of VD group and $54.0 \%$ of CS group were urban areas residents. In addition, $51.4 \%$ and $62.8 \%$ of both groups respectively reported that their monthly income was sufficient.

Table 3. Distribution of the studied groups according to their gynecologic and sexual history ( $n=277)$.

\begin{tabular}{|c|c|c|c|c|c|c|}
\hline \multirow{2}{*}{ Variables } & \multicolumn{2}{|c|}{ Vaginal delivery $n=140$} & \multicolumn{2}{|c|}{ Cesarean section $\mathbf{n}=137$} & \multirow{2}{*}{$\chi^{2}$} & \multirow{2}{*}{$P$ value } \\
\hline & No & $\%$ & No & $\%$ & & \\
\hline \multicolumn{7}{|c|}{ History of circumcision } \\
\hline Yes & 133 & 95.0 & 128 & 93.4 & \multirow[t]{2}{*}{0.313} & \multirow[t]{2}{*}{$>0.05$} \\
\hline No & 7 & 5.0 & 9 & 6.6 & & \\
\hline \multicolumn{7}{|c|}{ Onset of menstruation after delivery } \\
\hline Yes & 83 & 59.3 & 95 & 69.3 & \multirow[t]{2}{*}{3.050} & \multirow[t]{2}{*}{$>0.05$} \\
\hline No & 57 & 40.7 & 42 & 30.7 & & \\
\hline Yes & 41 & 29.3 & 44 & 32.1 & \multirow[t]{2}{*}{0.261} & \multirow[t]{2}{*}{$>0.05$} \\
\hline No & 99 & 70.7 & 93 & 67.9 & & \\
\hline \multicolumn{7}{|c|}{ Time of resumption of sexual intercourse after delivery } \\
\hline Fifth week & 13 & 9.3 & 7 & 5.1 & \multirow[t]{3}{*}{0.225} & \multirow[t]{3}{*}{$>0.05$} \\
\hline Sixth week & 109 & 77.9 & 105 & 76.6 & & \\
\hline Seventh week & 18 & 12.8 & 25 & 18.2 & & \\
\hline \multicolumn{7}{|c|}{ Frequency of sexual intercourse after birth } \\
\hline 3-4 weeks & 9 & 6.5 & 4 & 2.9 & 1.370 & $>0.05$ \\
\hline
\end{tabular}

$\chi^{2}$ : Chi-Square test

Table 3 indicates no significant differences $(\mathrm{p}>0.05)$ between VD and CS groups in relation to the history of circumcision, onset of menstruation, time and frequency of sexual intercourse after delivery and calm environment during intercourse. It was found that $95.0 \%$ and $93.4 \%$ of both VD and CS groups respectively were circumcised. Moreover, $59.3 \%$ of VD group and $69.3 \%$ of CS group were experienced the onset of menstruation after delivery. Also,

Table 4. Distribution of the studied groups according to their husband information and their need for consultation regarding sexual issues ( $n=277)$.

\begin{tabular}{|c|c|c|c|c|c|c|}
\hline \multirow{2}{*}{ Variables } & \multicolumn{2}{|c|}{ Vaginal delivery $n=140$} & \multicolumn{2}{|c|}{ Cesarean section $n=137$} & \multirow{2}{*}{ FET } & \multirow{2}{*}{$P$ value } \\
\hline & No & $\%$ & No & $\%$ & & \\
\hline \multicolumn{7}{|c|}{ Occupational status of the husband } \\
\hline Working & 139 & 99.3 & 135 & 98.5 & 0.359 & $>0.05$ \\
\hline Not working & 1 & 0.7 & 2 & 1.5 & & \\
\hline
\end{tabular}

$70.7 \%$ and $67.9 \%$ of both groups respectively didn't find calm environment during intercourse. With regard to the time of resumption of sexual intercourse after delivery $77.9 \%$ and $76.6 \%$ of both groups respectively were resumed sexual intercourse sixth week after delivery. Regard to frequency of sexual intercourse after birth, $66.4 \%$ and $67.9 \%$ of VD and CS groups respectively indicated 1-2 weeks interval. 


\begin{tabular}{|c|c|c|c|c|c|c|}
\hline \multirow{2}{*}{ Variables } & \multicolumn{2}{|c|}{ Vaginal delivery $n=140$} & \multicolumn{2}{|c|}{ Cesarean section $n=137$} & \multirow{2}{*}{ FET } & \multirow{2}{*}{$P$ value } \\
\hline & No & $\%$ & No & $\%$ & & \\
\hline \multicolumn{7}{|l|}{ Suffering from chronic illness } \\
\hline Yes & 0 & 0.0 & 2 & 1.5 & 2.059 & $>0.05$ \\
\hline No & 140 & 100.0 & 135 & 98.5 & & \\
\hline $\begin{array}{l}\text { Husband age (Mean } \pm \text { SD) } \\
\text { Need for consultation regarding sexual issues }\end{array}$ & \multicolumn{2}{|c|}{$33.52 \pm 4.12$} & \multicolumn{2}{|c|}{$34.02 \pm 5.23$} & $\mathrm{t}=0.976$ & $>0.05$ \\
\hline Yes & 111 & 79.3 & 117 & 85.4 & 1.779 & $>0.05$ \\
\hline
\end{tabular}

FET: Fisher's exact test, t: Independent t test

Table 4 represents that there were no statistically significant differences $(p>0.05)$ between VD and CS groups in the term of husbands' age, occupational status, suffering from chronic illness and need for consultation regarding sexual issues.

Table 5. The Differences of the FSFI mean score between vaginal delivery and cesarean section groups. $(n=277)$.

\begin{tabular}{|c|c|c|c|c|c|}
\hline \multirow{2}{*}{ Variables } & \multirow{2}{*}{ Maximum score } & Vaginal delivery $n=140$ & Cesarean section $n=137$ & \multirow{2}{*}{ t test } & \multirow{2}{*}{$P$ value } \\
\hline & & Mean \pm SD & Mean \pm SD & & \\
\hline Desire & 6 & $3.64 \pm 0.56$ & $3.58 \pm 0.65$ & 0.764 & $>0.05$ \\
\hline Arousal & 6 & $3.11 \pm 0.77$ & $3.32 \pm 0.64$ & 0.851 & $>0.05$ \\
\hline Lubrication & 6 & $3.60 \pm 0.69$ & $3.51 \pm 0.55$ & 1.125 & $>0.05$ \\
\hline Orgasm & 6 & $3.26 \pm 0.53$ & $3.49 \pm 0.51$ & 1.072 & $>0.05$ \\
\hline Satisfaction & 6 & $3.70 \pm 0.59$ & $3.68 \pm 0.45$ & 0.285 & $>0.05$ \\
\hline Pain & 6 & $4.09 \pm 1.24$ & $4.65 \pm 1.41$ & 1.120 & $>0.05$ \\
\hline
\end{tabular}

$\mathrm{t}$ : Independent $\mathrm{t}$ test

Table 5 shows the differences of the FSFI mean score between VD and CS groups. There were no statistically significant differences $(\mathrm{P}>0.05)$ between VD and CS groups as regard to all elements of FSFI including desire, arousal, lubrication, orgasm, satisfaction and pain. Moreover, total sexual function score in both groups were 21.41 \pm 2.82 and 22.27 \pm 2.27 , respectively, which indicated no statistically significant difference between the groups $(\mathrm{P}>0.05)$.

Table 6. The differences of the SQOL mean score between vaginal delivery and cesarean section groups. $(n=277)$.

\begin{tabular}{|c|c|c|c|c|c|}
\hline \multirow{2}{*}{ Variables } & \multirow{2}{*}{ Maximum score } & Vaginal delivery $n=140$ & Cesarean section $n=137$ & \multirow{2}{*}{ t test } & \multirow{2}{*}{$P$ value } \\
\hline & & Mean \pm SD & Mean \pm SD & & \\
\hline Psychosexual feelings & 42 & $21.02 \pm 3.96$ & $20.80 \pm 4.61$ & 1.373 & $>0.05$ \\
\hline Sexual and relationship satisfaction & 30 & $18.34 \pm 3.41$ & $18.78 \pm 3.21$ & 1.098 & $>0.05$ \\
\hline Self-worthlessness & 18 & $7.25 \pm 2.06$ & $7.72 \pm 2.37$ & 0.972 & $>0.05$ \\
\hline Sexual repression & 18 & $9.62 \pm 2.18$ & $9.75 \pm 2.39$ & 0.447 & $>0.05$ \\
\hline Total SQOL & 108 & $56.25 \pm 7.17$ & $55.05 \pm 7.87$ & 1.317 & $>0.05$ \\
\hline
\end{tabular}

$\mathrm{t}$ : Independent $\mathrm{t}$ test

Table 6 clarifies that, there were no statistically significant differences $(\mathrm{P}>0.05)$ between VD and CS groups regarding SQOL total and subtotal mean score including psychosexual feelings, sexual and relationship satisfaction, self-worthlessness and sexual repression.

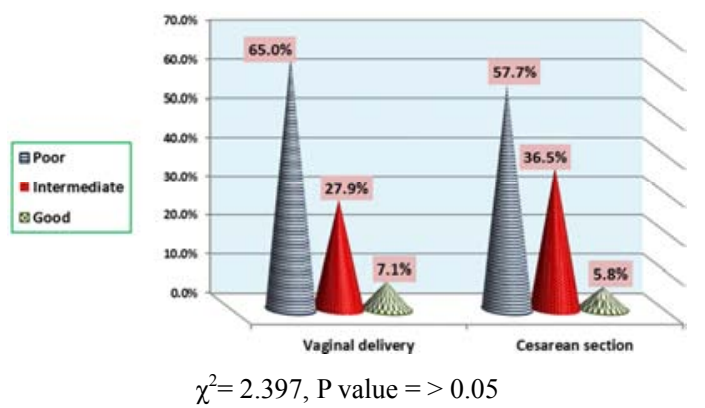

Figure 1. The relationship between the studied subjects mode of delivery and their sexual function level after delivery $(n=277)$.

Figure 1 portrays that, there was no statistically significant difference $(\mathrm{P}>0.05)$ between VD and CS groups regarding their sexual function level after delivery. where $65 \%$ of VD group and $57.7 \%$ of CS group had poor sexual function level after delivery. Only $7.1 \%$ and $5.8 \%$ of both groups respectively had good sexual function level after delivery.

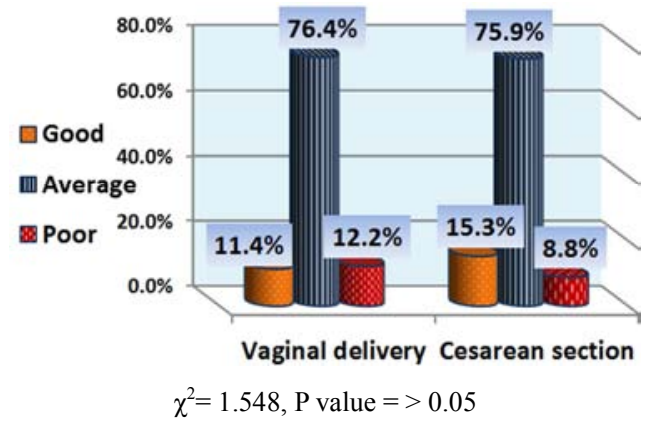

Figure 2. The relationship between the studied subjects mode of delivery and their SQOL level after delivery $(n=277)$. 
Figure 2 illustrates that, there was no statistically significant difference $(\mathrm{P}>0.05)$ between $\mathrm{VD}$ and CS groups regarding their SQOL level after delivery. Whereas $76.4 \%$ of VD group and $75.9 \%$ of CS group had an average level of SQOL after delivery. Only $11.4 \%$ and $8.8 \%$ of both groups, respectively had good level.

Table 7. Correlation coefficient between the total FSFI score and SQOL total score among the studied groups.

\begin{tabular}{lcc}
\hline \multirow{2}{*}{ Variables } & \multicolumn{2}{c}{ FSFI } \\
\cline { 2 - 3 } & $\boldsymbol{r}$ & $\boldsymbol{P}$ \\
\hline SQOL & 0.449 & $<0.01^{* *}$ \\
\hline
\end{tabular}

**A highly statistical significant correlation $(\mathrm{p} \leq 0.01)$

Table 7 clarifies that, there was a positive highly statistically significant correlation between studied subjects FSFI total score and SQOL total score. $(\mathrm{P}<0.01)$

\section{Discussion}

Pregnancy and delivery are one of the most significant periods of women's life that causes hormonal and bodily alterations which could have major effects on sexual function. One of the most important concerns affecting the stability of marriage is sexual function, so its problem can lead to divorce or separation of the couple. [11]

The results of this study will be discussed in frame of previously mentioned research questions. The present study finding revealed that there were no significant differences $(p$ $>0.05$ ) between VD and CS groups in relation to their age, educational level, occupation, residence and monthly income. Also, in relation to their husbands' information. These findings mean that the two groups under study are homogenous and comparable. These results were in line with Dabiri et al. and Amiri et al. [32, 33] where the former had studied "the effect of mode of delivery on postpartum sexual functioning in primiparous women". The latter had investigated "the difference of the sexual function after the normal VD and the CS". They pointed out that, there was no difference between the groups (VD and CS groups) with regard to demographic characteristics including age, education and occupation.

The present study results indicated absence of any significant differences $(\mathrm{p}>0.05)$ between VD and CS group with regard to their history of circumcision, onset of menstruation, time of resumption of sexual activity, frequency of sexual intercourse after delivery and calm environment during intercourse. The first intercourse after delivery may give rise to many concerns. Such as concerns related to dyspareunia, the possibility of becoming pregnant again, the episiotomy or CS wound, the relationship between the partners, the sense of lost attractiveness, or any negative memories related to delivery, may contribute to the woman's decision to delay resuming sexual intercourse after delivery. [34] The present study results illustrated that three quarters of both VD and CS groups were resumed sexual intercourse sixth week after delivery, with no significant difference between both groups. This finding may be attributed to that the resumption of sexual activity within six weeks postpartum is generally prohibited based on religious and cultural beliefs as a Muslim countries [35] The finding is similar to that of Dabiri et al. [32] who had stated that no statistically significant difference was observed between the two groups regarding their resuming sexual intercourse after delivery. Also, Alum et al. [36] who had studied "factors associated with early resumption of sexual intercourse among postnatal women in Uganda" reported that more than half of their studied subjects had resumed sexual intercourse by 6 weeks postpartum. Moreover, Barbara et al. [8] who had studied "the impact of mode of delivery on female postpartum sexual functioning" showed that the type of delivery did not significantly affect time to resumption of intercourse.

On the other hand Anzaku and Mikah [37] who conducted their study in Nigeria to evaluate "postpartum resumption of sexual activity and sexual morbidity among Nigerian women". They had reported that sexual intercourse was resumed by more than two third of women with a mean time to resuming sexual intercourse of 8.2 weeks postpartum. This difference in time of resumption of postpartum sexual intercourse between the current study and the study of Anzaku and Mikah may be attributable to diverse religious and cultural beliefs and sexual attitudes of women in different parts of the world.

With regard to the onset of menstruation after childbirth, no significant difference was found between VD and CS groups. This finding is in the same line with Alesheikh et al. [26] who had studied "the relationship between mode of delivery and sexual function in nulliparous women" found that the mode of delivery did not significantly affect the onset of menstruation among their studied groups.

Regarding research question 1 the current study results confirmed that there were no statistically significant differences $(\mathrm{P}>0.05)$ between $\mathrm{VD}$ and $\mathrm{CS}$ groups regarding all elements of FSFI including desire, arousal, lubrication, orgasm, satisfaction and pain. Moreover, total sexual function score in both groups were 21.41 \pm 2.82 and $22.27 \pm 2.27$, respectively, which indicated no statistically significant differences $(\mathrm{P}>0.05)$ between the groups. These findings are consistent with the findings of at least other five studies. First, Baghdari et al. [38] had conducted a study entitled "comparison of women's sexual function after natural childbirth and $\mathrm{CS}$ in women referring to the healthcare centers of Mashhad". Reported no statistical difference was shown in sexual function between natural childbirth and CS groups. Second, Hosseni et al. [39] in their study entitled "sexual function of primiparous women after elective CS and normal VD" followed the women for two years after delivery and reported that there was no difference between mode of delivery and sexual function. Third, De Souza et al. [40] had conducted a prospective study to evaluate "the effects of mode of delivery on postpartum sexual function". They showed that no significant difference in the sexual function of women 
having a CS compared with women having a VD at 12 months after childbirth. Fourth, previously mentioned study of Alesheikh et al. [26] which revealed no statistically significant difference between VD and CS groups ( $\mathrm{P}=0.509)$. Fifth, Malchi et al. [25] who had assessed "the relationship between modes of delivery and sexual function in primiparous women, and concluded that, there is no relationship between mode of delivery and sexual function of primiparous women. Sixth, Kahramanoglu et al. [41] who had studied "the impact of mode of delivery on the sexual function of primiparous women" found that CS is not superior to VD in terms of conservation of normal sexual function, regardless of short-term postpartum effects.

On the contrary, at least two other studies disagreed with the current study finding. First, Al-Sherbeny [24] who had conducted a comparative study in Egypt to "evaluate the impact of birth trauma on female sexual activity in primiparous women" using FSFI. Demonstrated that women had unrepaired perineal tears and CS reported significantly higher FSFI scores compared to those had repaired perineal tears or episiotomy three months postpartum. Second, the previously mentioned Barbara et al. study [8] which mentioned that women who experienced an operative VD had poorer scores on arousal, lubrication, orgasm, and total sexual functioning compared with the CS group and lower orgasm scores compared with the spontaneous VD group $(P$ $<0.05)$. This discrepancy between the current study results and those of the latter studies may be attributed to the differences of comparative groups among the studies. In the contradicting studies, the participants were divided to different categories according to the status of perineum to episiotomy, repaired perineal tears, and unrepaired perineal tears. While in the current study there is no possibility to compare between the different categories because all VD group were undergoing episiotomy.

Regarding research question 2 the current study findings revealed no statistically significant differences $(\mathrm{P}>0.05)$ between VD and CS groups regarding total and subtotal SQOL mean score including psychosexual feelings, sexual and relationship satisfaction, self-worthlessness and sexual repression. There are many studies that assess health related quality of life among VD and CS, but a few studies have focused on women's postpartum SQOL. However, the current results are consistent with some studies but vary from some previous studies; in hand with these findings, Varghese et al. [42] who had conducted a study in India entitled "sexual dysfunction among young married women" documented that the common disorders included reduce desire and arousal and orgasmic disorders and those had sexual dysfunction had a significantly poorer quality of life in general and had impaired social relationships. In fact, neglect sexual problem lead to feeling of reduced femininity and sexual failure, low selfconfidence, absence of security, and feeling inferior in front of a husband. Therefore, these problems lead to many social problems such as crime, divorce, drug addiction and physical and mental disorders. [43, 11]

Mousavi et al. [44] who had evaluated the quality of life after VD and CS, reported different results, and found that women with VD were more satisfied with their sexual lives and bodily appearance in the postpartum period than women with CS. This difference with current study could be due to the difference in sample size, study design or demographic differences.

The present study findings cannot confirm the protective factor for sexual dysfunction of caesarean section; indeed, in current study more than two third of VD group and more than half of CS group had poor sexual function level after delivery indicating sexual dysfunction. Only less than one tenth of both groups had good sexual function level after delivery with no statistically significant difference $(\mathrm{P}>$ 0.05 ) between VD and CS groups. The decrease in postpartum sexual function in women in both groups may be attributed to a hypo estrogenic state that can happen due to breast feeding; emotional changes such as the altering body image; fatigue due to the baby's needs; and the quality of the relation with her husband. In this regard the previously mentioned study of Amiri et al. [33] which showed that there was no significant difference between primiparous women who had VD through midiolateral episiotomy and those who experienced CS with regard to their sexual function level. In addition, Laganà et al. [45] conducted study to evaluate "the quality of sexual activity of women during postpartum period in relation to the mode of delivery". Found that female sexual dysfunction represent more than two third of their studied subjects with no evidence and significant relation between mode of delivery and onset of female postpartum sexual dysfunction. Moreover, Lurie et al. [46] evaluated "sexual function after childbirth by the mode of delivery". Concluded that elective CS was not associated with a protective effect on sexual function after birth.

There are two very recent studies conducted by Rezaei et al. and Ghorat et al. [35, 47] The former studied "postpartum sexual functioning and it's predicting factors among Iranian women". He found more than three quarters of the participants had sexual dysfunction. The latter evaluated "long term effect of VD and CS on female sexual function in primipara mothers" showed that delivery type has no long-term effect on female sexual function and appropriate education about the sexual issues after delivery and effect of birth giving on sexual function are necessary for this group of society. Accordingly, the findings of this study highlight the importance of educating pregnant women who request a CS about the advantages and disadvantages of this procedure.

On the other hand Holanda et al. [48] who studied "sexual dysfunction and associated factors reported in the postpartum period". Found that the prevalence of sexual dysfunction was $43 \%$ among postpartum women and the type of delivery one of the associated factors whereas VD with suture represented a threefold higher risk for sexual dysfunction when compared to the CS birth. The cause of the difference in findings between Holanda et al. study and that of the present study is probably due to the difference in obstetrical data. While 
Holanda et al. study conducted on different parity and included $44.5 \%$ primiparous women only, in the current study all subjects are primiparous women.

Regarding research question 3 the correlations between studied subjects FSFI score and SQOL score were investigated in the current study. Accordingly, there was a positive highly statistically significant correlation $(\mathrm{P}<0.01)$ between the studied subjects sexual function scores and their SQOL scores. This finding suggests poorer sexual function could have a negative impact on SQOL and overall quality of life. This result was supported by Hosseini-Tabaghdehi et al.[49] who had studied "the prevalence and predictors of female sexual dysfunction", reported that sexual dysfunction leads to reduced quality of life among women and dissatisfaction in relation to others. Furthermore, Varma et al. [50] investigated "sexual functioning and quality of life of women with opioid dependence, showed significant correlation between quality of life and sexual functioning. $(p=0.0004)$. Finally, Mohammed et al. [19] in their study entitled "sexual function after childbirth according to the mode of delivery" recommended encouraging women to disclose their sexual complains and worries with their physicians in order to improve their SQOL. Therefore, to enhance the SQOL in postpartum women with sexual dysfunction, more attention should be made on educational intervention to increase the awareness about sexual issues after child birth.

\section{Conclusion}

Based on the overall findings of the present study and answering of research questions it can be concluded that, there were no statistically significant differences between VD and CS groups as regard to postpartum sexual function and SQOL. The findings also stated that there was a positive highly statistically significant correlation between the women sexual function score and their SQOL score.

\section{Recommendations}

a. Nurses should implement health education classes for pregnant women regarding the advantages and disadvantages of vaginal and cesarean delivery in order to change their concept of delivery and develop a positive attitude towards vaginal delivery.

b. Nurses should provide sexual education for women during postpartum period to enhance sexual functioning and SQOL.

c. Further study is required to evaluate the postpartum sexual dysfunction and its associated factors.

d. Replication of the present study on larger sample, and different geographical area in Egypt.

\section{Acknowledgements}

The authors would like to thank all women who willingly participated in this study.

\section{References}

[1] Golmakani, N., Dormohammadi, M., \& Mazloum, S. R. Survey Of sexual satisfaction and marital satisfaction during postpartum at primiparous women referred to health care centers of Mashhad, Iran. The Iranian Journal of Obstetrics, Gynecology and Infertility. 2013; 16 (55):7-13.

[2] Mccool, M., Theurich, M., \& Apfelbacher, C. Prevalence and Predictors of Female Sexual Dysfunction: A Protocol For A Systematic Review." Systematic Reviews. 2014; 3 (1):75-80.

[3] Ozgoli, G., Sheikhan, Z., Dolatian, M., \& Valaee, N. The Survey of Obstacle and Essentiality Health Providers for Sexual Health Evaluation in Women Referring to Health Centers Related of Shahid Beheshti University Of Medical Sciences. Pejouhandeh. 2014; 19 (4):175-83.

[4] Bien, A., Rzońca, E., Palus, G., \& Lenkiewicz, E. Factors affecting sexual activity of women after childbirth. Journal Of Public Health, Nursing and Medical Rescue, 2016; 18 (2):647-55.

[5] Leeman, L. M., \& Rogers, R. G. Sex After Childbirth Postpartum Sexual Function. Obstet Gynecol, 2012; 119 (3):58-66.

[6] Enferm, A. B. Sexual dysfunction and associated factors reported in the postpartum period, 2014; 27 (6):573-8.

[7] Leal 1, I., Lourenço, S., Oliveira 1, R., Carvalheira, A., \& Maroco, J. Sexual function in women after delivery: Does episiotomy matter?. Health, 2012; 6 (5): 356-363.

[8] Barbara, G., Pifarotti, P., Facchin, F., Cortinovis, I., Dridi, D., Ronchetti, C., Calzolari, L., \& Vercellini P. Impact of Mode of Delivery on Female Postpartum Sexual Functioning: Spontaneous Vaginal Delivery and Operative Vaginal Delivery vs. Cesarean Section. J Sex Med. 2016 Mar; 13 (3):393-401. doi: 10.1016/j.jsxm.2016.01.004. Epub 2016 Feb 5.

[9] Lumbiganon, P., Laopaiboon, M., Gulmezoglu, A. M., Souza, J. P., Taneepanichskul, S., Ruyan, P., et al. Method of delivery and pregnancy outcomes in Asia: the WHO global survey on maternal and perinatal health 2007-08. Lancet. 2010; 375 (9713):490-499. doi: 10.1016/S0140-6736 (09) 61870-5.

[10] Mi, J., and Liu, F., Rate of caesarean section is alarming in China. Lancet. 2014; 383 (9927):1463-4. doi: 10.1016/S01406736 (14) 60716-9.

[11] Torkzahrani, S. H., Banaei, M, 1., Ozgoli, G.1., Azad, M., Emamhadi, M. A. Postpartum Sexual Function; Conflict in Marriage Stability: A Systematic Review, International Journal of Medical Toxicology and Forensic Medicine. 2016; 6 (2): 88-98.

[12] Vettorazzi, J., Marques, F., Hentschel, H., Ramos, J. G. L., Martins-Costa, S. H., \& Badalotti, M. Sexuality and the postpartum period: a literature review. Rev HCPA. 2012; 32 (4):473-9.

[13] Sayasneh A. \& Pandeva I. Postpartum Sexual Dysfunction: A literature review of risk factors and role of mode of delivery, BJMP 2010; 3 (2):316.

[14] Elkowessny, D., Salama, H., Abu-Nazel, M., \& Gobashy, S. Help Seeking Behavior for Female Sexual Dysfunction Among Middle Aged Egyptian Women. European Psychiatry, 30 (1) 2015; P 1392. 
[15] Rizvi, S. J., Yeung, N. W., \& Kennedy, S. H. Instruments to measure sexual dysfunction in community and psychiatric populations. J Psychosom Res., 2011; 70: 99-109.

[16] Chedraui, P., Perez-Lopez, F. R., Sanchez, H., Aguirre, W., Martinez, N., Miranda. O., Plaza, M. S., Schwager, G., Narvaez, J., Quintero, J. C., Zambrano, B. Assessment of sexual function of mid-aged ecuadorian women with the 6item Female Sexual Function Index. Maturitas 2012; 71: 407412.

[17] Tsai, T. F., Yeh, C. H., \& Hwang, T. I. S. Female sexual dysfunction: physiology, epidemiology, classification, evaluation and treatment. Urological Science, 2011; 22:713.

[18] Maasoumi, R., Lamyian,1., Montazeri, A., Azin, S. A., Aguilar-Vafaie, M. E., \& Hajizadeh, E., The sexual quality of life-female (SQOL-F) questionnaire: translation and psychometric properties of the Iranian version, Reproductive Health, 2013; 10 (25):1-6.

[19] Mohammed, Y. S., Hassan, H. M., Al Dinary, A. M., \& Rashed, N. S., sexual function after child birth according to the mode of delivery. AAMJ., 2014; 12 (4):264-284.

[20] Acele, E. O., \& Karaçam, Z. Sexual problems in women during the first postpartum year and related conditions. Journal of Clinical Nursing, 2011; 21, 929-937.

[21] Prairie, B. A., Scheier, M. F., Matthews, K. A., Chang, C. C., \& Hess, R. A. higher sense of purpose in life is associated with sexual enjoyment in midlife women. Menopause .2011; 18 (8):839-844.

[22] Pancholy, A. B., Goldenhar, L., Fellner, A., N., Crisp, C., Kleeman, S., \& Pauls, R. Resident education and training in female sexuality: results of a national survey. J Sex Med. 2011; 8 (2):361-6.

[23] Cacciatore, A., Giordano, R., Romano, M., La Rosa, B., \& Fonti, I. Putative protective effects of cesarean section on pelvic floor disorders. J Prenat Med. 2010 Jan; 4 (1):1-4.

[24] Al-Sherbeny, M. F. Evaluation of Impact of Birth trauma on Female Sexual Activity in Primiparous women: A Comparative Study using Female Sexual Function Index. J Am Sci 2012; 8 (7):289-296.

[25] Malchi, F., Afshari, P., Bostani, H., \& Rasekh, A. Assessment of the relationship between modes of delivery and sexual function in primiparous women perspective, International Journal of Pharmaceutical Research \& Allied Sciences, 2016, 5 (3):307-310.

[26] Alesheikh, A., Jaafarnejad, F., Esmaili, H., \& Asgharipour, N. The Relationship between Mode of Delivery and Sexual Function in Nulliparous Women. Journal of Midwifery and Reproductive Health. 2016; 4 (3): 635-643.

[27] Eniel, A. O., \& Petri, E. Pregnancy, childbirth, and sexual function: perceptions and facts. Int Urogynecol J 2014; 25:514

[28] Symonds, T., Boolell, M., \& Quirk, F., Development of a questionnaire on sexual quality of life in women. J Sex Marital Therapy, 2005; 31:385-397.

[29] Rosen, R., Brown, C., Heiman, J., Leiblum, S., Meston, C., Shabsigh, R., Ferguson, D., \& D'Agostino, R. The female sexual function index (FSFI): A multidimensional self-report instrument for the assessment of female sexual functions. $\mathrm{J}$ Sex Marital Therapy, 2000; 26 (2): 191-208.

[30] Mohammadi, K. H., Heydari, M., \& Faghihzadeh, S. The female sexual function index: validation of the Iranian version. Payesh. 2008; 7 (3): 269-278.

[31] Cronbach, L., Coefficient alpha and the internal structure of tests. Psychometrika. 1951; 16 (5):297-334.

[32] Dabiri, F., Yabandeh, A. P., Shahi, A., Kamjoo, A., \& Teshnizi, S. H. The Effect of Mode of Delivery on Postpartum Sexual Functioning in Primiparous Women. Oman Med J. 2014 Jul; 29 (4): 276-279. doi: 10.5001/omj.2014.72.

[33] Amiri, F. N., Omidvar, S., Bakhtiari, A., Yazdani, S. \& Hajiahmadi, M. Comparison of Sexual Function in Primiparous Women Pre-Pregnancy and Postpartum: Difference of the Sexual Function after the Normal Vaginal Delivery and the Cesarean Section. Health, 2015; 7: 13791386. http://dx.doi.org/10.4236/health.2015.710152

[34] Hipp, L. E., Kane Low, L., \& van Anders, S. M. Exploring women's postpartum sexuality: social, psychological, relational, and birth-related contextual factors. J Sex Med 2012; 9 (9): 2330- 4.

[35] Rezaei, N., Azadi, A., Sayehmiri, K., Valizadeh, R. Postpartum sexual functioning and it's predicting factors among Iranian women. Malays J Med Sci. 2017;24 (1):94103. https://doi.org/10.21315/mjms2017.24.1.10

[36] Alum, A. C., Kizza, I. B., Osingada, C. P., Katende, G., \& Kaye, D. K. Factors associated with early resumption of sexual intercourse among postnatal women in Uganda. Reprod Health. 2015; 12: 107.

[37] Anzaku, A. S., \& Mikah, S. Postpartum Resumption of Sexual Activity, Sexual Morbidity and Use of Modern Contraceptives Among Nigerian Women in Jos. Annals of Medical and Health Sciences Research. 2014; 4 (2): 210-216.

[38] Baghdari, N., Anbaran, Z. K., Mazlom, S. R., \& Golmakani, N. Comparison of women's sexual function after natural childbirth and cesarean section in women referring to the healthcare centers of Mashhad. The Iranian Journal of Obstetrics, Gynecology and Infertility. 2012; 15 (30):8-14.

[39] Hosseini, L., Iran-Pour, E., \& Safarinejad, M. R. Sexual function of primiparous women after elective cesarean section and normal vaginal delivery. Urol J. 2012 Spring; 9 (2): 498504.

[40] De Souza, A., Dwyer, P. L., Charity, M., Thomas, E., Ferreira, C. H. J., \& Schierlitz, L. The effects of mode delivery on postpartum sexual function: a prospective study. BJOG 2015; 122:1410-1418.

[41] Kahramanoglu, I., Baktiroglu, M., Hamzaoglu, K., Kahramanoglu, O, Verit, F. F., \& Yucel, O. The impact of mode of delivery on the sexual function of primiparous women: A prospective study. Arch Gynecol Obstet. 2017 Apr; 295 (4):907-916. doi: 10.1007/s00404-017-4299-7. Epub 2017 Feb 6 .

[42] Varghese, K. M., Bansal, R., Kekre, A. N., \& Jacob, K. S. Sexual dysfunction among young married women in southern India. Int Urogynecol J. 2012 Dec; 23 (12):1771-1774. doi: 10.1007/s00192-012-1782-3. Epub 2012 Apr 25. 
[43] Kaviani, M., Rahnavard, T., Azima, S., Emamghoreishi, M., Asadi, N., \& Sayadi, M. The Effect of Education on Sexual Health of Women with Hypoactive Sexual Desire Disorder: A Randomized Controlled Trial." International Journal of Community based Nursing and Midwifery. 2014; 2 (2):94102.

[44] Mousavi, S. A., Mortazavi, F., Chaman, R., \& Khosravi, A. Quality of life after cesarean and vaginal delivery. Oman Med J 2013. Jul; 28 (4):245-251 10.5001/omj.2013.70

[45] Laganà, A. S., Burgio, M. A., Ciancimino, L., Sicilia, A., Pizzo, A., Magno, C., Butticè, S., \& Triolo, O. Evaluation of recovery and quality of sexual activity in women during postpartum in relation to the different mode of delivery: a retrospective analysis. Minerva Ginecol. 2015 Aug; 67 (4):315-20. Epub 2014 Jun 19.

[46] Lurie, S., Aizenberg, M., Sulema, V., Boaz, M., Kovo, M., Golan, A., \& Sadan, O. Sexual function after childbirth by the mode of delivery: a prospective study. Arch Gynecol Obstet. 2013 Oct; 288 (4):785-792. doi: 10.1007/s00404-013-2846-4. Epub 2013 Apr 16.
[47] Ghorat, F., Esfehani, R. J., Sharifzadeh, M., Tabarraei, Y., \& Aghahosseini, S. S. Long term effect of vaginal delivery and cesarean section on female sexual function in primipara mothers. Electron Physician. 2017; 9 (3):3991-3996. doi: 10.19082/3991. eCollection 2017.

[48] Holanda L. J. B., Abuchaim, E. V., Coca, K. P., \& Vilhena Abrão, A. F. Sexual dysfunction and associated factors reported in the postpartum period. Acta paul. enferm. São Paulo Nov./Dec. 2014; 27 (6) http://dx.doi.org/10.1590/19820194201400093

[49] Hosseini-Tabaghdehi, M., Hajikazemi, E., \& Hossieni, F. Prevalence and Predictors of Female Sexual Dysfunction. Mazandaran Journal of Medical Sciences. 201122 (91):102107.

[50] Varma, A., Sethi, R., Hartman, DW., Herbertson, R., \& Kablinger, A. S., et al. Sexual Functioning and Quality of Life of Women with Opioid Dependence Maintained on Buprenorphine/Naloxone vs Community Norms. J Subst Abuse Alcohol, 2014; 2 (1): 1005. Available at: https://www.jscimedcentral.com/SubstanceAbuse/substanceab use-2-1005.pdf 